Discussion. The size of the ridge remaining after resection correlated well with the late results: the best results followed its complete removal. Chronic mechanical irritation of ten produces adhesions between the calcaneal tendon and the posterior surface of the calcaneus, with loss of the radiolucent retrocalcaneal recess (Pavlov et al 1982). At operation this gives the appearance of a higher tendon insertion, which may explain the incidence of incomplete resection. The amount of bone to be resected should be determined from pre-operative radiographs. This allows any adhesions between bone and tendon to be divided, without danger to the insertion itself. There is no evidence that the calcaneus is dangerously weakened by full resection.

During eversion and inversion of the foot the calcaneal tendon glides on the dorsal surface of the calcaneum. After resection, there should be no contact between the tendon and the bone above its insertion, even in full ankle dorsiflexion. If the line of resection is too steep, contact may occur and cause irritation of the calcaneal tendon and chronic tendinitis.

The aim of surgery is to produce a gently sloping, smooth surface above the level of the insertion of the Achilles tendon which does not make contact with the tendon (Fig. 2).

The author gratefully acknowledges the help of Mr Douglas McGeorge, Whiston Hospital, Merseyside, in correcting the manuscript.

No benefits in any form have been received or will be received from a commercial party related directly or indirectly to the subject of this article.

\section{REFERENCES}

Haglund P. Beitrag zur Klinik der Achillessehne. Z Orthop Chir 1927; 49:49-58.

Inman VT, Ed. DuVries' surgery of the foot. 3rd ed. St Louis: CV Mosby Co, 1973:491-4.

Pavlov H, Heneghan MA, Hersh A, Goldman AB, Vigorita V. The Haglund syndrome: initial and differential diagnosis. Radiology $1982 ; 144: 83-8$.

\title{
SPINDLE-CELL SARCOMA OF THE HAND MAY PRESENT AS A BENIGN RECURRENT NODULE
}

\author{
R. A. POWER, S. MANEK, C. J. MCCULLOUGH
}

Dupuytren's disease presents as fascial thickening with or without joint contracture, most commonly affecting the ring and little fingers. An isolated nodule at an atypical site is extremely unusual.

Case report. A 52-year-old woman presented with a $2 \mathrm{~cm}$ mass in the web between her middle and index fingers, showing induration and early ulceration. Excision biopsy indicated a highly cellular sarcoma with sheets of small spindle cells, occasional storiform areas (Fig. 1) and a high mitotic count. The immunopathological markers s.100, Desmin and Vimentin were negative and did not allow further classification of the tumour.

Ten years previously a subcutaneous nodule, thought to be a dermoid cyst, had been excised from the same site. Histological examination at that time showed broad bands of connective tissue, mainly hypocellular, but with focal areas of increased cellularity (Fig. 2). This was considered to be Dupuytren's disease.

R. A. Power, FRCS Ed, Orthopaedic Registrar

S. Manek, MSc, MB BS, Pathology Registrar

C. J. McCullough, MA, FRCS, Consultant Orthopaedic Surgeon

Northwick Park Hospital, Watford Road, Harrow, Middlesex HAl 3UJ, England.

Correspondence to Mr R. A. Power at 26 Collins Street, Blackheath, London SE3 0UG, England.

(C) 1992 British Editorial Society of Bone and Joint Surgery 0301-620X/92/2R41 \$2.00

J Bone Joint Surg [Br] 1992; 74-B:316-7.

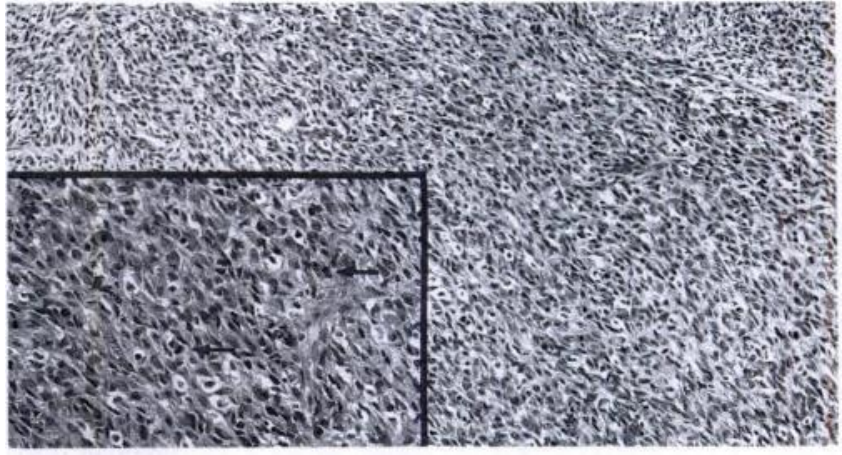

Figure $1-\times 5$; inset $\times 25$; haematoxylin and eosin.

Six years after the initial excision, a recurrent swelling was excised. The second specimen showed more fibroblast-like cells arranged in short, irregular bundles. Bands of collagen were less evident. There were a few giant cells and occasional bizarre nuclei but no mitotic activity (Fig. 3). The diagnosis at this stage was nodular fasciitis rather than Dupuytren's disease.

After the diagnosis of sarcoma, ray amputation of the index and middle fingers was performed. All resection margins were clear of tumour, there was no associated lymphadenopathy and CT scans of the chest and abdomen showed no metastatic spread.

Discussion. Spindle-cell sarcomas represent about half of all adult soft-tissue tumours (Coindre et al 1988). There are several histological types, but $20 \%$ remain unclassi- 


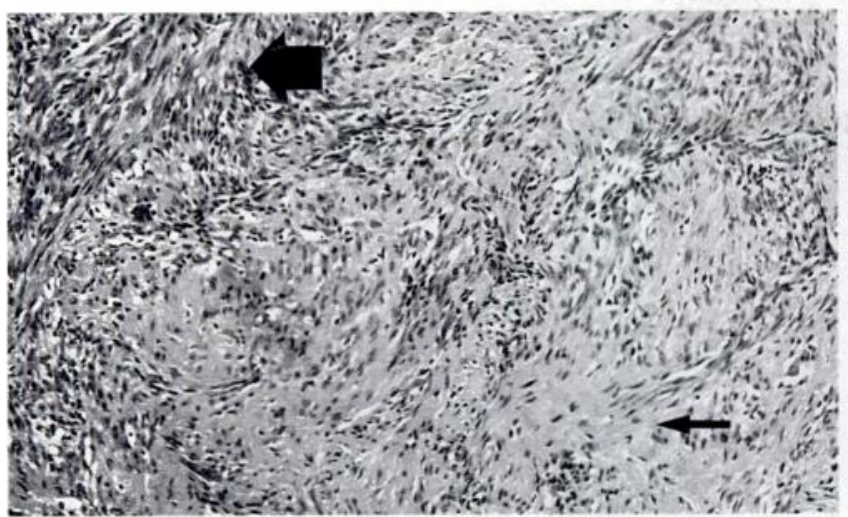

Figure 2 - Initial excision ten years earlier, showing hypocellular area with prominent connective tissue bands (thin arrow) and focal cellular area (thick arrow) $(\times 10$; haematoxylin and eosin).

fied. In the hand they may arise de novo or complicate reactive processes or benign neoplasms (Rosenberg and Schiller 1987). Malignant transformation of Dupuytren's disease has not, however, to our knowledge, been reported.

The evolution of spindle-cell tumour from a lowgrade to a high-grade sarcoma over many years is unusual, but can occur in nerve-sheath tumours (Carstens and Schrodt 1969) and in malignant fibrous histiocytomas. We reviewed all our histological specimens: it seems likely that the original lesion, excised ten years previously, was a low-grade spindle-cell sarcoma. It would have been extremely difficult to make a confident diagnosis then.

The second specimen, excised six years later, was more easily acceptable as a spindle-cell sarcoma and the histological diagnosis of nodular fasciitis was probably incorrect, although differentiation can be very difficult.

The absence of positive soft-tissue markers made it

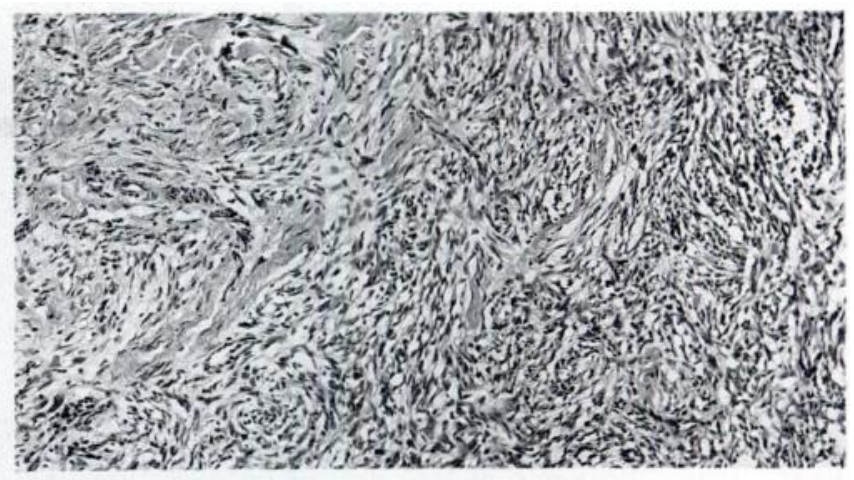

Figure $3-\times 5$; haematoxylin and eosin.

impossible to sub-classify the tumour but the slow clinical progress and the increasingly evident malignancy suggest that it is either a nerve-sheath tumour or a malignant fibrous histiocytoma.

The appearance of Dupuytren's disease in an atypical site in the absence of Dupuytren's diathesis should arouse suspicion of low-grade malignancy. Very careful assessment of the pathology is necessary.

The authors would like to thank Dr C. Fisher, FRCPath, Consultant Pathologist, Royal Marsden Hospital, for reviewing the pathology.

No benefits in any form have been received or will be received from a commercial party related directly or indirectly to the subject of this article.

\section{REFERENCES}

Carstens PHB, Schrodt GR. Malignant transformation of a benign encapsulated neurilemoma. Am J Clin Path 1969; $51: 144-9$.

Coindre JM, Bui NB, Bonichon F, Mascarel I, Trojani M. Histopathologic grading in spindle cell soft tissue sarcomas. Cancer 1988; 61 :2305-9.

Rosenberg AE, Schiller AL. Soft tissue sarcomas of the hand. Hand Clin $1987 ; 3: 247-61$

\section{CORRECTION}

Horibe S, Shino K, Taga I, Inoue M, Ono K. Reconstruction of lateral ligaments of the ankle with allogeneic tendon grafts.

J Bone Joint Surg [Br] 1991 ; 73-B :802-5.

The authors of this article have informed us that the grading of symptoms they used in Table I, while it was reported by Sefton et al (1979), was originally proposed by Good, Jones and Livingstone in 1975. The correct reference is given below:

Good CJ, Jones MA, Livingstone BN. Reconstruction of the lateral ligaments of the ankle. Injury 1975; 7:63-5. 